\title{
A Unique Case of Rehabilitation of a Young Girl with a Bilateral Above the Knee Stumps and Spina Bifida
}

\author{
Koryukov AA* \\ Multidisciplinary rehabilitation center "ReaSunMed», St. Petersburg, Russia \\ *Corresponding author: Koryukov AA, Multidisciplinary rehabilitation center “ReaSunMed», St. Petersburg, Russia
}

\section{ARTICLE INFO}

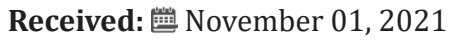

Published: 幽 November 17, 2021

Citation: Koryukov AA. A Unique Case of Rehabilitation of a Young Girl with a Bilateral Above the Knee Stumps and Spina Bifida. Biomed J Sci \& Tech Res 40(1)-2021. BJSTR. MS.ID.006395.

Keywords: Thigh Stumps; Spina Bifida; Surgical Treatment; Pro/Orthotics

\section{ABSTRACT}

A clinical example of rehabilitation of a 26-year-old girl who underwent amputation of both thighs in childhood and who moves in a wheelchair is considered. Concomitant pathology of the spinal cord - the presence of meningomyelocele and open Spina bifida did not allow the fabrication of leg prostheses on the stump of the thighs without preliminary surgical preparation. Long-term sitting position and movement only in a wheelchair led to the formation of contact chronic osteomyelitis of the pelvic bones. A number of staged operations for the treatment of osteomyelitis, correction of spinal deformity in the Spina bifida area were performed. Then, primary prosthetics of the stumps of both thighs was performed, in combination with orthosis (corset made of thermoplastic material) of the lumbar spine. This allowed the patient to be verticalized, who was able to stand and move with the help of a walker. This observation demonstrates a positive result of a multidisciplinary approach to the rehabilitation of patients with a very complex combined pathology of the musculoskeletal system: the spine and lower extremities.

\section{Introduction}

Prosthetics after amputation of the lower extremities is a complex problem in the medical and social rehabilitation of patients. The higher the level of amputation, the more difficulties encountered in the manufacture of leg prostheses. However, only with the help of prostheses, the patient will be able to stand and move independently, using aids. According to [1], 50,000 amputations are performed annually in Russia. Of these, $51 \%$ - for obliterating diseases of the vessels of the lower extremities, $26.2 \%$ - for diabetes mellitus. Thigh amputations account for $61.5 \%$, of which paired thigh amputations account for 59\%. It is known that after amputations of the lower extremities in $70 \%$ of cases, there is a presence of vicious stumps, including those complicated by pain. In addition, the higher the level of amputation, the more difficulties are encountered in the manufacture of a prosthesis in which the patient can move independently or use aids for walking [2]. Combinations of leg amputation with congenital malformations of the musculoskeletal system and, in particular, the spine, for example, Spina bifida, are especially difficult. The most common and significant clinical form of Spina bifida is myelomeningocele (MMC), in which a hernia forms with the involvement of the membranes and tissues of the spinal cord [3-8]. The condition, which occurs in about 1 child in 1000 newborns [9,5]), is characterized by the inability of the lumbosacral spinal neural tube to close during embryonic development.

Exposed nerve tissue degenerates in utero, resulting in various neurological deficits and varies with the level of lesion $[3,5,10]$. In this form of Spina bifida, a part of the spinal cord emerges through the spinal defect in the form of a "pouch" with the spinal cord [11]. It can be covered with skin, in other cases, the brain tissue itself and nerve roots can go out, and the very severity of neurological manifestations and disorders will be associated with the localization and severity of the spinal cord defect [12]. Myelomeningocele (MMC) affects the quality of life in childhood, adolescence and adulthood, making it difficult for individuals, families and society as a whole [3,13-20]. And this is due to the fact that non-infection in $80 \%$ of cases is accompanied not only by paralysis of the legs, but 
also by dysfunction of the bladder and intestines [8]. Despite these problems, sick people are preserved intellectually or emotionally. They also go to school, study at institutes, want and can play sports. In Russia there are a world champion in fencing, the $37^{\text {th }}$ world tennis player, a member of the Russian Paralympic ski / biathlon team, a champion of Russia, there is a world champion in wheelchair dancing in 2015 [16]. For the treatment of the defect, as a rule, surgical correction is used, in most cases immediately after birth [21,22]. However, in recent years in Russia, the United States and other countries intrauterine correction of Spina bifida in the fetus has been widely used [23-28].

It reduces the risk of ventriculoperitoneal shunting and increases the level of cognitive and motor development compared with the post-natal treatment group. We consider the rehabilitation of patients with a similar injury to the spine and with vicious paired amputations of the lower extremities at above the knee level to be the most difficult. To put the patient on his feet, atypical prostheses should be made, including non-standard sockets for primary prosthetics. Primary prostheses are made primarily in order to form the volumetric dimensions of the stumps. They also restore support, teach the patient the principles of virtualization, balance, and movement over short distances. Material and methods. A clinical example of successful rehabilitation of a 26-year-old female patient is presented, with depressed amputation stumps of both thighs in the middle third and flexion contractures in the hip joints at an angle of 15 degrees in combination with Spina bifida (The case from my work in 2015, in the "Russian Scientific Center" Restorative Traumatology and Orthopedics them. acad. G.A. Ilizarov “, Kurgan- city, Russia (director - A.V. Gubin, MD). In connection with Spina bifida and paralysis of the lower extremities, accompanied by also severe deformities of the both feet, the patient underwent above the knee amputation at the age of 14 years at the place of residence. Later she lived in one of the orphanages in Russia, moving only in a wheelchair.

Prolonged sitting in a wheelchair led to the development of contact osteomyelitis of the right half of the pelvic bones. It can be assumed that urinary incontinence played a role in the development of osteomyelitis. The ischial bone was also involved in the inflammatory process, namely, it serves as the main supporting landing site for the stump in the socket of the above the knee prosthesis. It was decided to preliminary prepare for prosthetics by step-by-step surgical treatment. At the first stage, specialists of the Department of Purulent Orthopedics (Dr. S.V. Mukhtyaev) performed reconstruction of the right ischium, necrectomy of sequestration, ultrasonic cavitation of the wound, drainage, with positive dynamics of treatment, and wound healing by primary intention (Figures 1-3).The second stage, together with neurosurgeons (S.O. Ryabykh, D.M.Savin, A.A. Koryukov).From the point of view of morphology, the macro preparation was represented by a rounded soft tissue formation (fat pouch) up to $6 \mathrm{~cm}$ in size, on the cut, brown-yellow tissue covered with skin up to $13 \mathrm{~mm}$ thick. The material contains fragments of thin skin with signs of papillary mutilation (Figure 4). The fragment contained adipose tissue with bundles of atrophied skeletal muscles, which should normally be absent. The presence of signs of skeletal muscle atrophy indicated a possible gradual degeneration due to the lack of normal function.

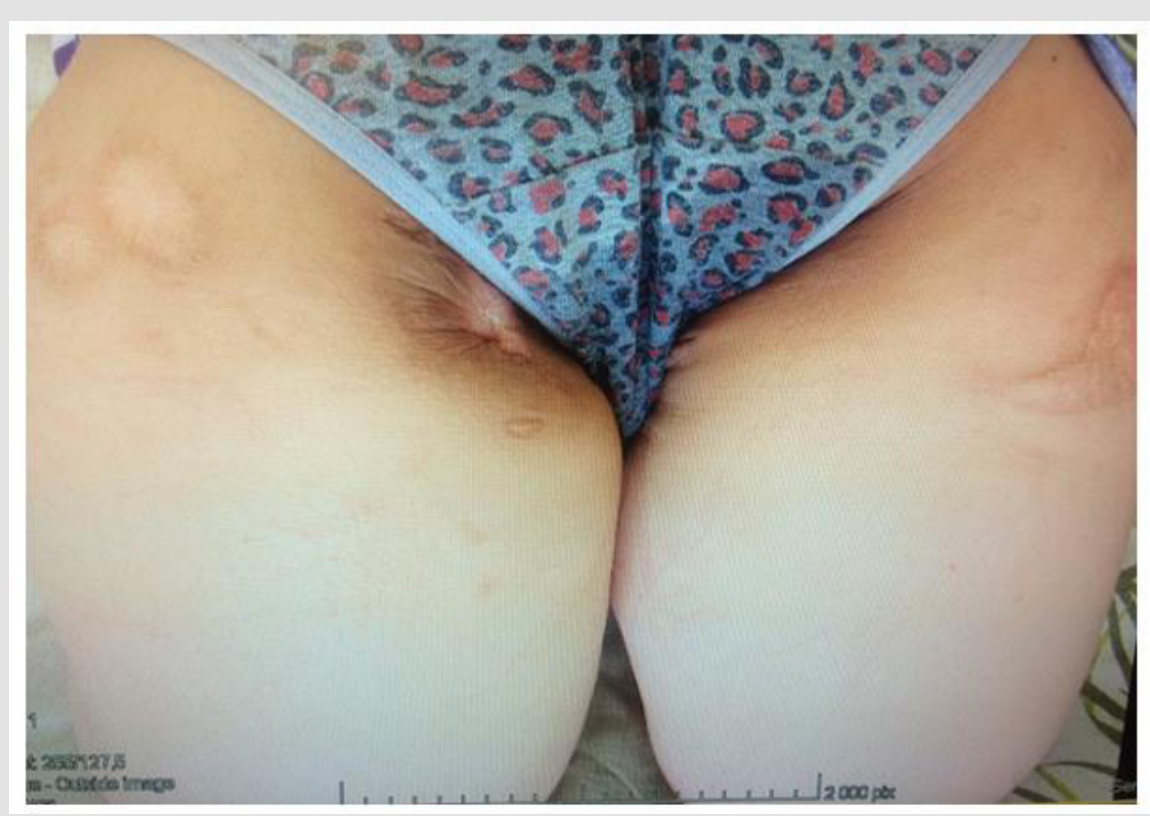

Figure 1: Photo of the dorsal surface of the patient's pelvis before treatment. The area of skin lesion in the area of damaged pelvic bones by contact chronic osteomyelitis is visualized. 


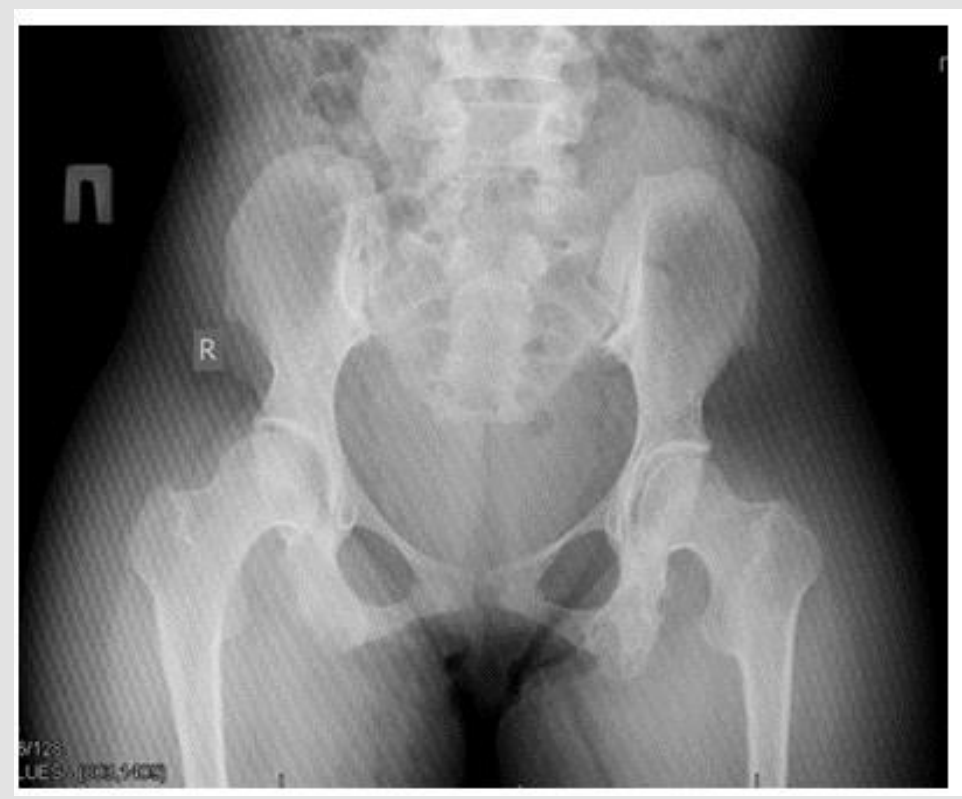

Figure 2: On radiographs of the pelvic bones, there is a heterogeneous structure and uneven contours of the ischial bones, confirming the presence of chronic osteomyelitis.

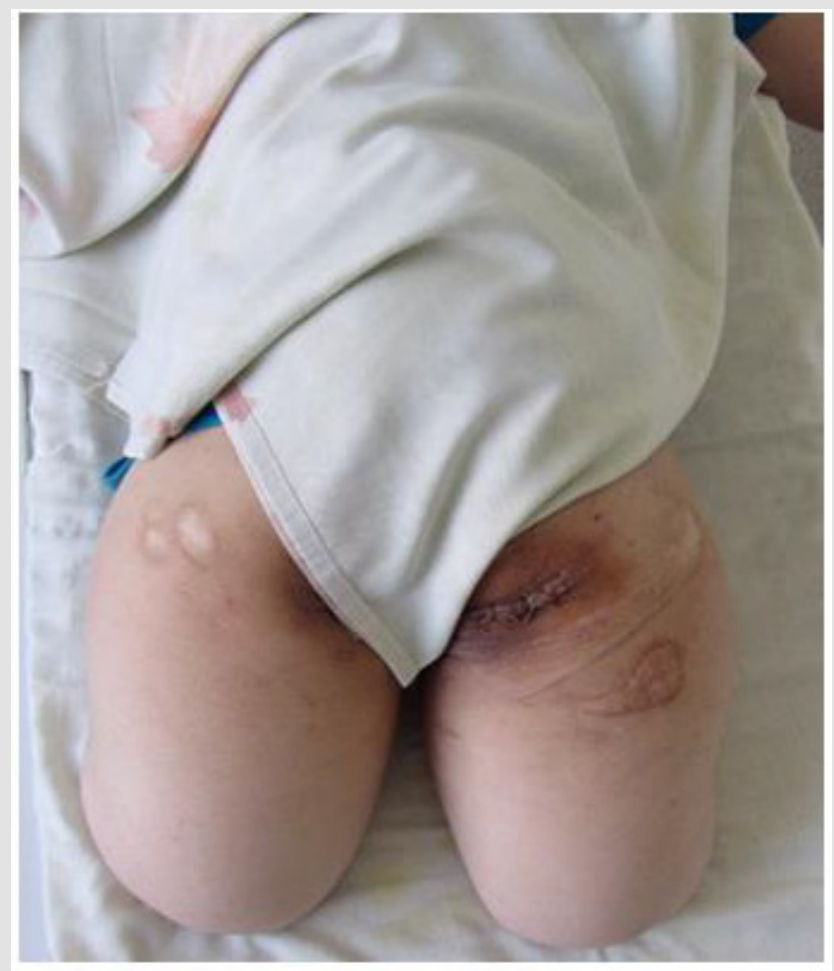

Figure 3: Reconstruction of the pelvic bones and sequestrectomy of the affected areas of the bone, ultrasonic cavitation and excision of the changed skin with the imposition of postoperative sutures were performed. 


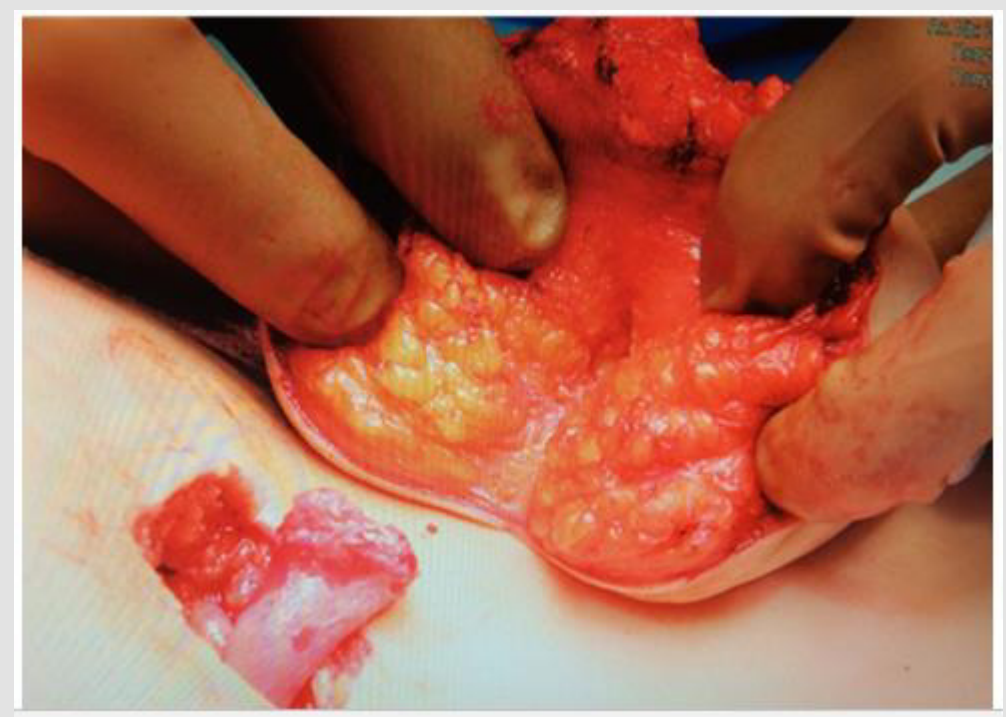

Figure 4: Intraoperative photo: isolated and excised lipomatous education, on the leg hernial sac of MMC.

After the healing of the postoperative wound in the lumbar region, a stage of restorative treatment was performed (special packing for extension in the hip joints, the application of elastic bandages on the above the knee stumps, exercises aimed at strengthening the muscles of the trunk and limbs). The patient was prepared for the production of express above the knee prostheses and spine orthoses (A.A. Koryukov, A.V. Reznik, S.P. Pukhov). Individual receiving sleeves made of thermoplastic, connected by means of hip joints with a rigid lumbar corset, ensured structural rigidity and stability of an upright position when walking (Figures 5a-5c). Such an assembly was necessary due to the long-term lack of support, the presence of small flexion contractures in the hip joints, and weakness of the back muscles. The stage of fitting the socket and corset, learning to walk on prostheses took about 2 weeks in total. The patient quickly mastered walking with prostheses, and therefore knee modules were installed in her 10 days later. The walking pattern has become more physiological. In addition, due to the bending of the legs in the knee joints, in prostheses, if necessary, it was possible to sit down (Figure 6). While walking, the woman leaned on a walker, and in the future she was recommended to use other available means - crutches with armrests and walking sticks (Figures 7a-c to 8).

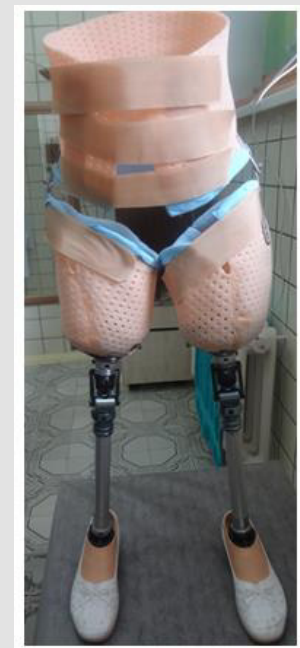

a

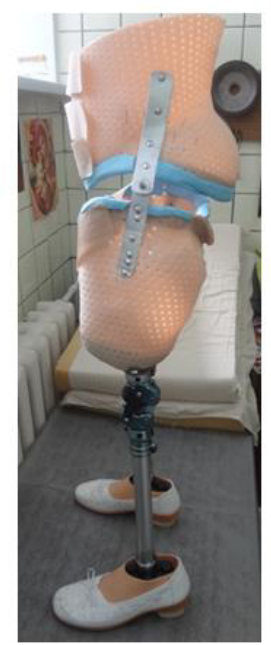

b

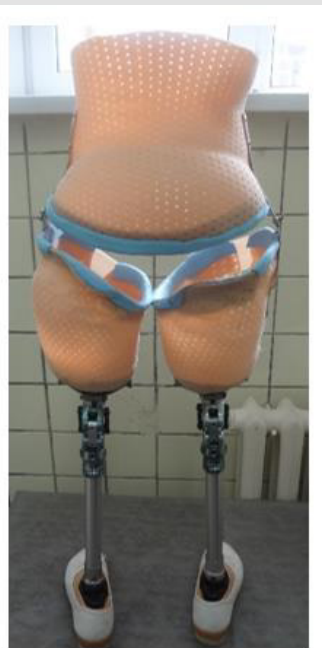

$\mathrm{C}$

Figure 5: Ready prosthesis and spine orthoses.

a) Front view,

b) Side and

c) Back. 


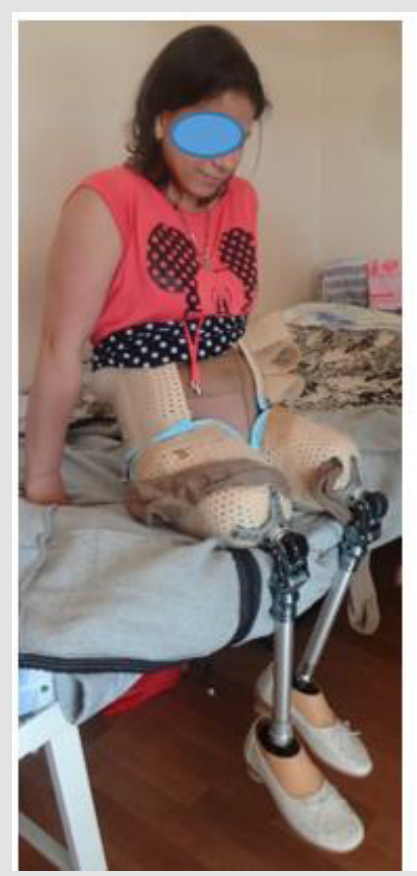

Figure 6: The patient in prostheses can sit freely if necessary.

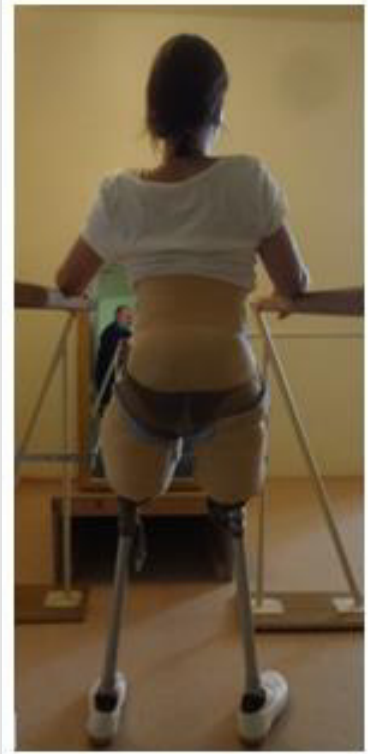

a

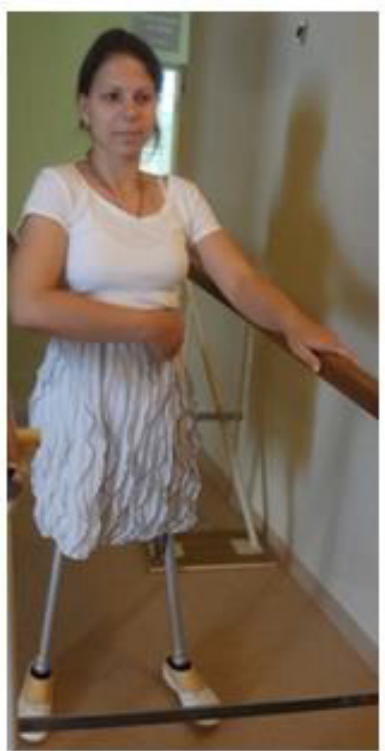

b

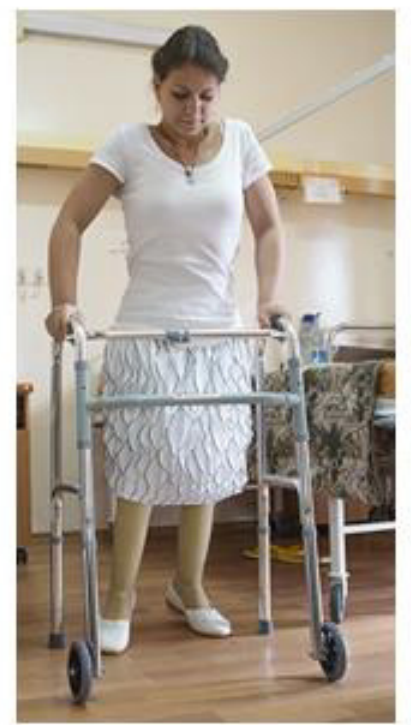

c

Figure 7: The patient's appearance in prostheses at the stage of mastering walking

a. Back view and

b. b-c: Front. 


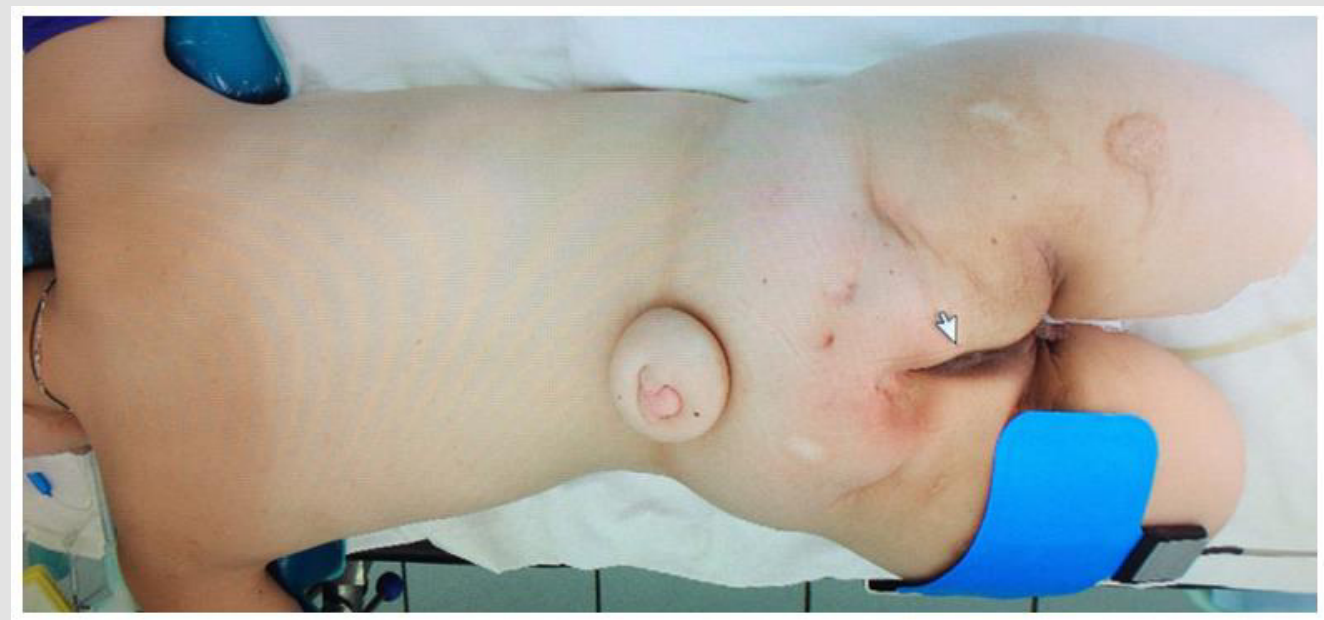

Figure 8: Photo of a patient with myelomeningocele of the lumbar spine before surgical treatment.

\section{Conclusion}

1. In non-standard, atypical situations of pathology of the musculoskeletal system, stage-by-stage medical preparation for prosthetics is required, including various types of surgical treatment.

2. The use of modern thermoplastic materials, even in a hospital, makes it possible in a short time to make any individual therapeutic and training prostheses.

3. For the first time in many years, the patient was able to move independently and improve the quality of life.

\section{Conflict of Interest}

None.

\section{References}

1. Zoloev GK (2015) Obliterating arterial disease. Surgical treatment and rehabilitation of patients with loss of limb: Monograph ( $2^{\text {nd }}$ Edn.)., In: GK Zoloev (Edt.)., Rev and add M Litterra, pp. 480.

2. Shvedovchenko IV, Shapiro KI (2006) Some features of the pathology of the musculoskeletal system and the doctor's tactics in patients who have undergone limb amputation. Traumatology and Orthopedics of Russia 1: $38-41$.

3. Hutchins GM, M Meuli, C Meuli Simmen, MA Jordan, DS Heffez, et al. (1996) Acquired spinal cord injury in human fetuses with myelomeningocele. Pediatr Pathol Lab Med 16(5): 701-712.

4. Stiefel D, Copp AJ, Meuli M (2007) Fetal spina bifida: Loss of neural function in utero. J Neurosurg 106(3): 213-221.

5. Copp AJ, Adzick NS, Chitty Lyn S (2015) Spina Bifida. Nature Reviews Disease Primers 1: 15007.

6. Baindurashvili AG, Batysheva TT, Bykova OV, Geldt VG (2017) Myelodysplasia in children (organization and provision of specialized medical care). Manual for doctors.

7. Kurtser MA, AG Prityko, EI Spiridonova (2020) Intrauterine surgical correction of myelomeningocele in the fetus and its outcomes: a pilot study. Pediatrics 99(1): 18-24.
8. https://kladzdor.ru/articles/mocheispuskaniestoma/Spina_Bifida_i_ narushenie_funkciy_mocheispuskaniya/

9. Dolk H, Loane M, Garne E (2010) The prevalence of congenital anomalies in Europe. Adv Exp Med Biol 686: 349-364.

10. Brender JD, Peter J Weyer, Paul A Romitti, Binayak P Mohanty, Mayura U Shinde, et al. (2013) Prenatal nitrate intake from drinking water and selected birth defects in offspring of participants in the national birth defects prevention study. Environ Health Perspect 121(9): 1083-1089.

11. Morozov SP, Polyakova OV, Yanovskaya NV (2020) The back is bifida Modern approaches and possibilities for diagnostics, treatment and rehabilitation. Journal of Practical Medicine 3: 32-37.

12. Popov IV, Syzdykov ED, Khatskel SB (2007) Spina bifida posterior as a manifestation of connective tissue dysplasia syndrome. Kazan Medical Journal 88(5-S): S140- S142.

13. Boudos RM, Mukherjee S (2008) Barriers to community participation: Teens and young adults with spina bifida. J Pediatr Rehabil Med 1(4): 303-310.

14. Kelly LM, Zebracki K, Holmbeck GN, Gershenson L (2008) Adolescent development and family functioning in youth with spina bifida. J Pediatr Rehabil Med 1(4): 291-302.

15. Holbein CE, Caitlin B Murray, Alexandra M Psihogios, Rachel M Wasserman, Bonnie S Essner, et al. (2013) A camp-based psychosocial Intervention to promote independence and social function in individuals with spina bifida: moderators of treatment effectiveness. J Pediatr Psychol 38(4): 412-424.

16. https://www.vogue.ru/beauty/chto-takoe-spina-bifida-i-kak-lechateto-zabolevanie-v-rossii

17. Bellin MH, Brad E Dicianno, Philip Osteen, Nienke Dosa, Elizabeth Aparicio, et al. (2013) Family satisfaction, pain, and quality-of-life in emerging adults with spina bifida: A longitudinal analysis. Am J Phys Med Rehabil 92(8): 641-655.

18. Freeman KA, Smith K, Adams E, Mizokawa S, Neville Jan A, et al. (2013) Is continence status associated with quality of life in young children with spina bifida. J Pediatr Rehabil Med 6(4): 215-223.

19. Murray CB, Lennon JM, Devine KA, Grayson N Holmbeck, Anna M Ros, et al. (2014) A longitudinal examination of health-related quality of life in children and adolescence with spina bifida. Journal of Pediatric Psychology 40(4): 419-430. 
20. Stubberud J, Langenbahn D, Levine B, Stanghelle J, Schanke AK, et al. (2014) Emotional Health and Coping in Spina Bifida After Goal Management Training: A Randomized Controlled Trial. Rehabil Psychol 60(1): 1-16.

21. Rintoul NE, Leslie N Sutton, Anne M Hubbard, Brian Cohen, Jeanne Melchionni, et al. (2002) A new look at myelomeningoceles: functional level, vertebral level, shunting, and the implications for fetal intervention. Pediatrics 109(3): 409-413.

22. Kulkarni AV, Jay Riva Cambrin, Samuel R Browd, James M Drake, Richard Holubkov, et al. (2014) Endoscopic third ventriculostomy and choroid plexus cauterization in infants with hydrocephalus: A retrospective Hydrocephalus Clinical Research Network study. J Neurosurg Pediatr 14(3): 224-229.

23. Adzick NS, Elizabeth A Thom, Catherine Y Spong, John W Brock $3^{\text {rd }}$, Pamela K Burrows, et al. (2011) A randomized trial of prenatal versus postnatal repair of myelomeningocele. N Engl J Med 364(11): 993-1004.
24. Adzick NS Fetal (2012) Surgery for myelomeningocele: Trials and tribulations. Isabella Forshall Lecture. J Pediatr Surg 47(2): 273-281.

25. Rychik J, Zhiyun Tian, Meryl S Cohen, Stanford G Ewing, David Cohen, et al. (2004) Acute cardiovascular effects of fetal surgery in the human. Circulation 110(12): 1549-1556

26. Li H, Fei Gao, Lili Ma, Junhong Jiang, Jianing Miao, et al. (2012) Therapeutic potential of in utero mesenchymal stem cell (MSCs) transplantation in rat fetuses with spina bifida aperta. J Cell Mol Med 16(7): 1606-1617.

27. Saadai P, Aijun Wang, Yvette S Nout, Timothy L Downing, Katrine Lofberg, et al. (2013) Human induced pluripotent stem cell-derived neural crest stem cells integrate into the injured spinal cord in the fetal lamb model of myelomeningocele. J Pediatr Surg 48(1): 158-163.

28. Cohen AR, James Couto, James J Cummings, Anthony Johnson, Gerald Joseph, et al. (2014) Position statement on fetal myelomeningocele repair. Am J Obstet Gynecol 210(2): 107-111.
ISSN: 2574-1241

DOI: 10.26717/BJSTR.2021.40.006395

Koryukov AA. Biomed J Sci \& Tech Res

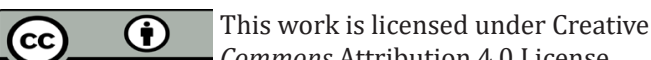

Submission Link: https://biomedres.us/submit-manuscript.php

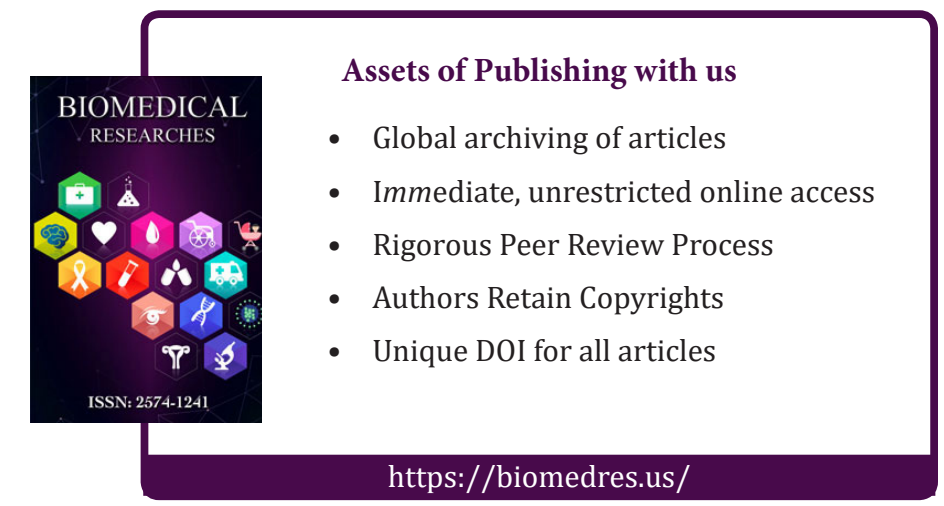

